\title{
The Advantages of Demographic Change after the Wave: Fewer and Older, but Healthier, Greener, and More Productive?
}

\author{
Fanny Kluge $^{1 *}{ }^{\text {, Emilio Zagheni }}{ }^{2}$, Elke Loichinger ${ }^{3,4}$, Tobias Vogt ${ }^{1}$ \\ 1 Laboratory of Survival and Longevity, Max Planck Institute for Demographic Research, Rostock, Germany, 2 Department of Sociology, University of Washington, Seattle, \\ Washington, United States of America, 3 International Institute for Applied Systems Analysis, Laxenburg, Austria, 4 Research Institute for Human Capital and Development, \\ Vienna University of Economics and Business, Vienna, Austria
}

\begin{abstract}
Population aging is an inevitable global demographic process. Most of the literature on the consequences of demographic change focuses on the economic and societal challenges that we will face as people live longer and have fewer children. In this paper, we (a) briefly describe key trends and projections of the magnitude and speed of population aging; (b) discuss the economic, social, and environmental consequences of population aging; and (c) investigate some of the opportunities that aging societies create. We use Germany as a case study. However, the general insights that we obtain can be generalized to other developed countries. We argue that there may be positive unintended side effects of population aging that can be leveraged to address pressing environmental problems and issues of gender inequality and intergenerational ties.
\end{abstract}

Citation: Kluge F, Zagheni E, Loichinger E, Vogt T (2014) The Advantages of Demographic Change after the Wave: Fewer and Older, but Healthier, Greener, and More Productive? PLoS ONE 9(9): e108501. doi:10.1371/journal.pone.0108501

Editor: Jennifer Beam Dowd, City University of New York (CUNY), United States of America

Received April 15, 2014; Accepted August 29, 2014; Published September 24, 2014

Copyright: (c) 2014 Kluge et al. This is an open-access article distributed under the terms of the Creative Commons Attribution License, which permits unrestricted use, distribution, and reproduction in any medium, provided the original author and source are credited.

Data Availability: The authors confirm that, for approved reasons, some access restrictions apply to the data underlying the findings. We stated that our data are available upon request. This is due to legal reasons as we obtained our data from a third party. To estimate age profiles of carbon emissions we used data from the Consumer Expenditure Survey (available at http://www.bls.gov/cex/) and economic input-output life cycle assessment tables (available at www.eiolca.net). The estimates of labor force participation by age, sex and highest level of educational attainment in 2008 in Germany and in Sweden are based on data from Eurostat, EU Labour Force Survey. The responsibility for all conclusions drawn from the data lies entirely with the authors. The data are available upon request from ESTAT-Microdata-access@ec.europa.eu. Data on assumptions and results for the education-specific population projections for Germany, 2008 to 2053, can be obtained from Elke Loichinger, IIASA (loiching@iiasa.ac.at). To estimate healthy life expectancy shares we use data from the German Socio Economic Panel from the DIW (German Institute for Economic Research). The data is available upon request from Michaela Engelmann (soepmail@diw.de). In addition, life expectancy estimates from the Human Mortality Database are used. The data can be obtained free of charge at www.mortality.org. For the last part, we use data from the Income and Expenditure Survey 2003. The data can be obtained from the German Federal Statistical Office, Service Wirtschaftsrechnungen und Zeitbudget (viiid-info@ destatis.de). In addition, the non-monetary results are estimated using the Time Use Survey 2001/02. The data are available upon request from the Auskunftsdienst "Einkommen, Konsum, Lebensbedingungen" of the Federal Statistical Office (forschungsdatenzentrum@destatis.de). National Transfer Account data can be obtained from Fanny A. Kluge, Max Planck Institute for Demographic Research (kluge@demogr.mpg.de).

Funding: Research reported in this publication was partially supported by the National Institute on Aging of the National Institutes of Health under Award Number R03AG045385 and by the Austrian Science Fund (FWF) Z171 G11. The funders had no role in study design, data collection and analysis, decision to publish, or preparation of the manuscript.

Competing Interests: The authors have declared that no competing interests exist.

*Email: kluge@demogr.mpg.de

\section{Introduction}

Countries around the globe are experiencing population aging. In developed societies, life expectancy has risen at a steady pace of about three months per year, and this trend is not expected to end [1]. At the same time, fertility fell considerably in almost all countries around the world. In Europe, three-quarters of the population live in countries with fertility below the replacement level [2]. Increasing longevity and low birth rates inevitably result in major changes in the observed age structure, with consequences for societal arrangements. The projected changes will affect numerous areas of life, such as family formation, labor market arrangements, the sustainability of public finances, and the environment.

Economic research has so far primarily stressed the negative effects of increasing life expectancy and declining fertility, such as the burden of increasing dependency ratios $[3,4]$, the dramatic effects on the labor market [5-8], and the effects of global aging on the macroeconomy $[9,10]$. Furthermore, a big branch of the literature focuses on the impact of population aging on the pillars of social security. According to numerous studies, health expenditures are going to increase [11-14], as are expenditures for longterm care $[15,16]$. Conversely, other studies find that population aging contributes little to the escalation of health care costs $[17,18]$. The increasing share of public pension expenditures of government budgets is also of great concern [19-22]. The observed and expected changes in the demographic composition are projected to cause different problems in different countries, depending mainly on the degree of reliance of the citizens on the public sector in old age and the generosity of public programs.

For most European countries, the most dramatic changes are expected to occur over the next three decades, during which a decreasing number of producers will have to care for an increasing number of consumers. After this transitional period, the popula- 
tions of these countries will, on average, be older and smaller; and the costs will be lower as smaller cohorts start entering retirement age. Therefore, while it is certainly true that the current and expected changes in age structure will have a negative impact on, for example, public finances, in the medium term, we expect to see much milder consequences in the long run. In fact, there are a number of ways in which population aging could represent an opportunity. We investigate five areas that can illustrate possible unintended positive consequences of population aging in the long run. We focus on the educational composition of the labor force, $\mathrm{CO}_{2}$ emissions in aging societies, intergenerational transfers in the form of bequests, developments in care need and healthy life expectancy, and the share of the lifetime spent working. These five examples demonstrate the potential positive long-term effects that are either directly or indirectly caused by population aging. Examples of direct consequences are lower $\mathrm{CO}_{2}$ emissions due to changing consumption patterns over the life cycle, and more balanced intergenerational transfers as the upward public transfers for public pensions are compensated for through higher inter-vivo transfers and bequests due to the lower number of siblings. An example of indirect consequences of population aging is the likely change in composition of the labor force due to the expected changes in the education structure.

Our study demonstrates the positive effects if the current conditions prevail. However, this is not necessarily the case: There will be some degree of behavioral adaptations of individuals, i.e., the findings are subject to change related to how far individuals in the future make decisions that deviate from the currently observed patterns. While it would be possible to speculate about the different coping strategies that may be implemented in the future, making such predictions is beyond the scope of this article. However, our results will give some indication of the potential magnitudes of expected effects. Hence, we intend to offer some basis for discussion about the possible advantages of population aging and how key age-dependent patterns could lead to changes that will entail important societal adjustments.

We mainly focus on Germany, not only because the country is a forerunner in terms of aging, but also because it has a very high level of public transfers and a huge industrial sector. These characteristics make Germany highly suitable for the envisaged analysis. The article is structured as follows: We first provide an overview of the population aging process in Germany. We then present five illustrative examples of areas in which aging might have advantageous side effects. In the remainder of the paper, we show why these developments can be important for policy-makers, and provide a concluding discussion.

\section{Aging in Germany}

We begin our analysis by presenting some descriptive figures on population aging in Germany. Our intention is to show that major demographic changes have happened in the past, and that ongoing changes are expected to shape the future until 2040. The main reason for these developments is the fact that the baby boomer cohorts are reaching retirement age. When this influential transition phase - which is expected to put pressure on social security programs and create more general sustainability issues has passed, a more "advantageous" population age distribution can be expected. Figure 1 compares the population age distributions for Germany in 2010 and 2060. While today individuals of working age represent the majority of the population, these cohorts will grow old in the coming decades. Thereafter, we can expect to see an older but more evenly distributed age structure.

Germany is at an advanced stage in the demographic transition for two main reasons: an early fertility decline and a rapidly increasing life expectancy. The TFR had already fallen far below the replacement level in the early 1970s and even today remains at around 1.4. At the same time, life expectancy is expected to increase further. In the medium-scenario UN projection, women are predicted to gain another 10 years of life expectancy over the course of the century. By 2060, female life expectancy at birth is expected to reach 90 years [23].

Already today, Germany's population has the second highest median age worldwide (44.3 years) only topped by Japan's median age of 44.9 years [24]. This makes Germany a forerunner in terms of aging, with a very steep rise in the old-age dependency ratio set to occur between 2020 and 2040. The economic support ratio shows an even more refined picture, as it considers the real dependencies, and is, for example, used to calculate demographic dividends [25]. In this case $\mathrm{SR}(\mathrm{t})=\mathrm{L}(\mathrm{t}) / \mathrm{N}(\mathrm{t})$ where $\mathrm{L}(\mathrm{t})$ is the population weighted by age-specific variation in productivity and $\mathrm{N}(\mathrm{t})$ is the population weighted by the variation by age in consumption. To calculate the support ratio, we use data on agespecific consumption and income patterns from the National Transfer Accounts project (see www.ntaccounts.org) to estimate the real consumption and income values for the population over the coming decades. The support ratio shows that, currently, about 0.8 producers take care of one consumer. In the decades to come, this ratio will fall to 0.6. Thus, Germany is an important case to study, as it is among the first of the countries that will experience a demographic future which almost all of the industrialized countries will eventually face.

As Germany likely faces a continuously low level of TFR and parallel increases in life expectancy, the aging process will occur at a rapid pace, which as stated earlier will lead to sustainability problems. While this is certainly the case in specific areas and for some transitional decades, we can expect the demographic changes to be moderate after 2050. We have identified important areas in which population aging can be even advantageous. These areas will be presented in the remaining sections of the paper.

\section{Methods}

We use various methods to show the likely advantageous effects of population aging in selected areas, but we will not describe these methods in detail here. Instead, at the beginning of each section, we will briefly present the data and methods used. The overall approach for all of the sections is comparable: we will show the underlying age patterns for each variable of interest, such as the CO2 emissions or the education-specific labor force participation level. This is intended to provide information on how age-sensitive our variables are. We will then project the information. Our focus is on a point in time relatively far in the future, when the demographic turmoil is likely to be over, and a smaller population with a less unbalanced age structure is anticipated. Our analysis mainly investigates what will happen if the current conditions prevail. We use age profiles of the monetary production and consumption, environmental conditions, the labor market, healthrelated conditions and time use variables observed today, and combine these with medium-term population forecasts, to show what happens to the results on the macro level if a different population structure were assumed. This basic forecast can give us important insights into how demography will alter the variables on the population level; and whether we will encounter an improvement in, for example, $\mathrm{CO}_{2}$ emissions after 2050, if only because having an older population is, on average, associated with lower consumption of energy-intensive goods. 


\section{0}

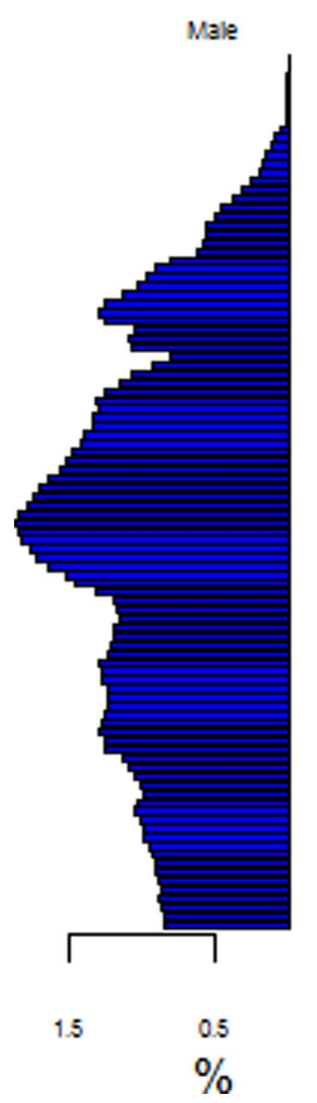

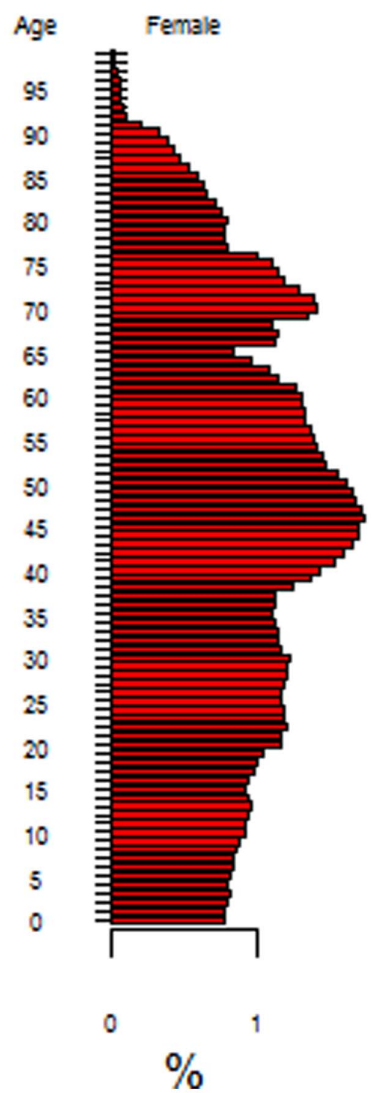

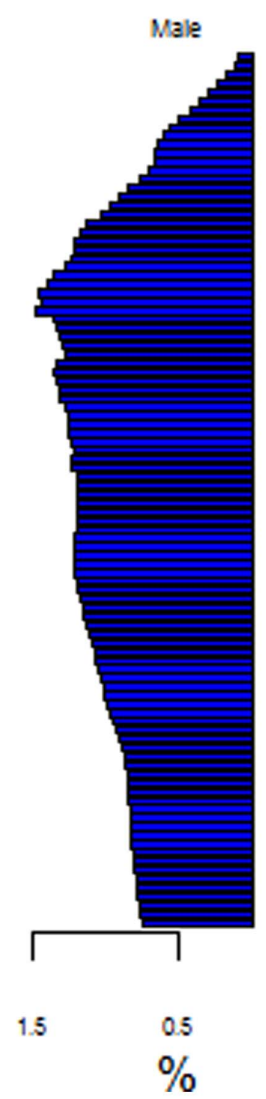

2060

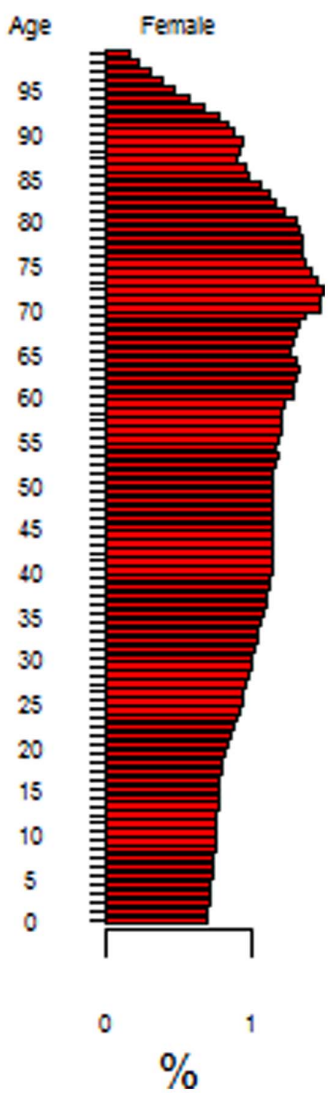

Figure 1. Population age distribution, Germany 2010 (left) and 2060 (right). Source: Statistisches Bundesamt (2012). doi:10.1371/journal.pone.0108501.g001

\section{Results}

\section{More productive? - Demographic change and the labor force}

Economic activity levels in Germany vary between age groups and between men and women, and they show the typical inverted $\mathrm{u}$-shape: the level is higher for middle-aged individuals than for younger and older people, and men are more likely to participate in market work than women (the "total" line in Figure 2). In addition to these known differences, there are also noticeable differences in labor force participation levels - our measure of economic activity - by individuals' highest levels of educational attainment. We created two distinct education categories: one that includes everyone with a tertiary degree (equivalent to ISCED level 5 or 6), and one that includes everyone who has a lower level of educational attainment (ISCED level 1 through 4). Figure 2 shows labor force participation levels in Germany across age, sex, and education for the year 2008, based on the European Labor Force Survey, EU LFS [26]. The year was deliberately chosen to avoid including the impact of the financial crisis. Labor force participation is defined according to the definition of the ILO, which means it includes the employed as well as the unemployed. The labor force participation rate is defined as the sum of employed and unemployed persons divided by the total number of people in the respective age, sex, and education category. The higher the level of education, the higher the level of labor force participation, and the smaller the differences between men and women. The total size of the German labor force was about 42.6 million in 2008, and one-quarter of the individuals in the labor force had a tertiary degree. This share was slightly higher among men than among women; or $27 \%$ and $23 \%$, respectively.

The fact that economic activity levels not only show distinct patterns by age and sex, but also by education, plays a crucial role when it comes to assessing the potential impact of changes in the size and structure of the labor force on economic growth. The consequences of population aging are only to a certain degree determined by a population's age structure. Labor productivity is not uniform, but varies along several dimensions, with one of them being the educational attainment levels of workers [10]. It might very well be the case that a smaller and older but - in terms of human capital - better equipped and more productive labor force can compensate for some of the expected declines in economic growth [27,28]. However, it is not the goal of this exercise to quantify these growth effects. Instead, we would like to show the potential changes in the composition of the German labor force that go beyond the usual projections by age and sex.

Before we can project the characteristics of the labor force in terms of age, sex, and education, we need not only the participation profiles along these three dimensions, but also the corresponding population projections. Using the multi-state cohort-component method, the German population was projected from 2008 to 2053 [29]. The starting population distribution in 2008 was calculated from the EU LFS. The specifications for future fertility, mortality, migration, and education transitions are 
Males

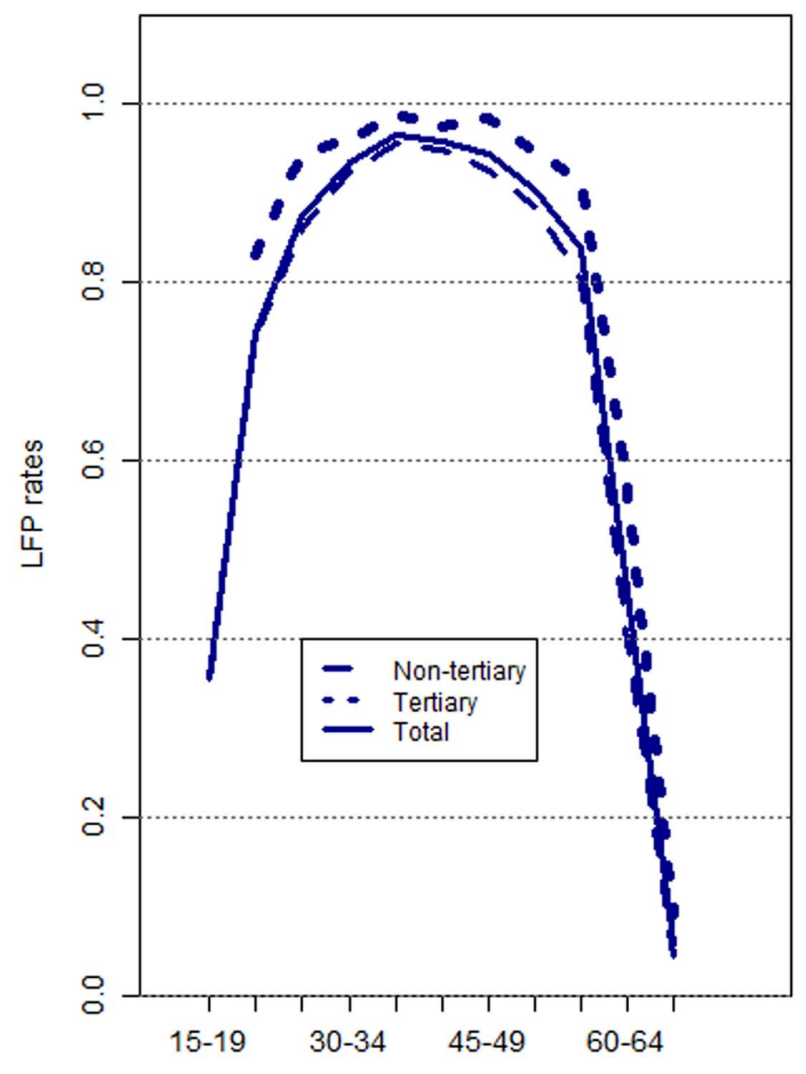

Age

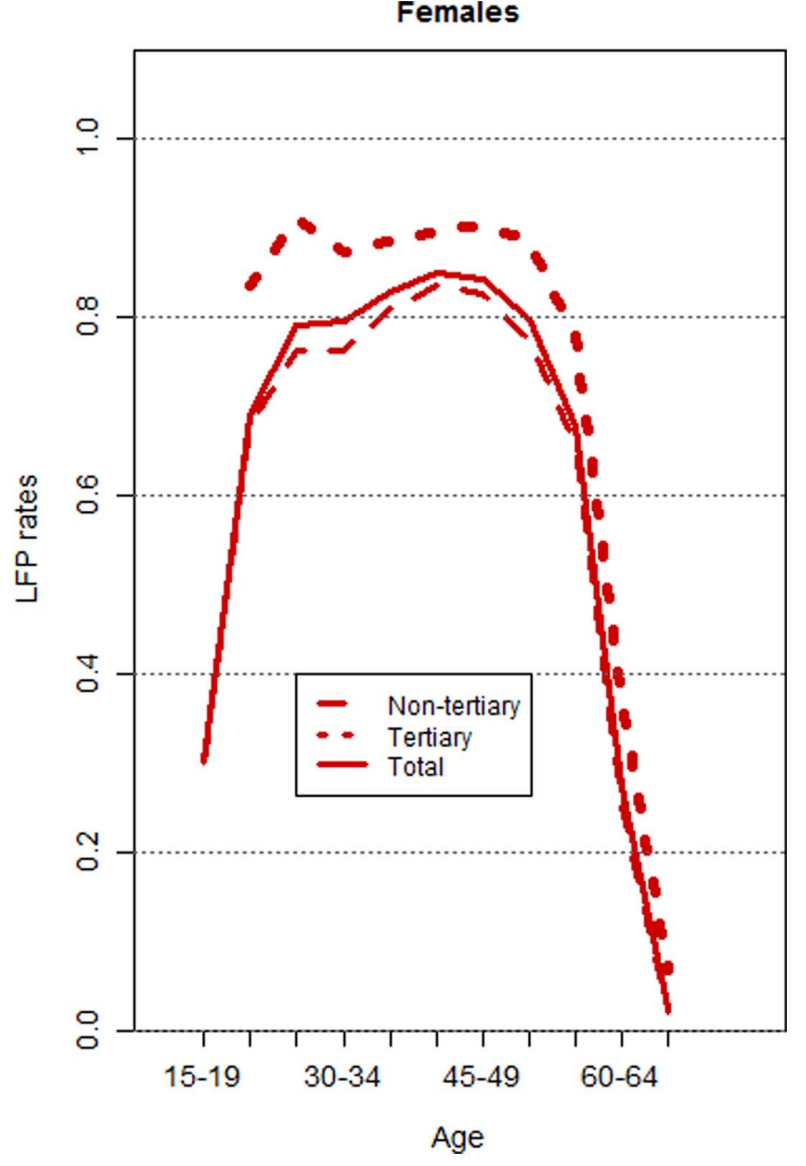

Figure 2. Labor force participation rates in Germany, by age, sex, and highest level of educational attainment, 2008. Source: EU LFS, own calculations.

doi:10.1371/journal.pone.0108501.g002

the same as those presented in [30]; with the only difference being that the assumptions about the future development of fertility, mortality, and migration have been updated using the 2011 Version of the World Population Prospects [23]. The education transitions came from the GET (Global Education Trend) scenario, which projected future transitions based on the development of historical global patterns of educational expansion. On the basis of these assumptions, our analysis showed that not only will larger shares of the younger cohorts attain tertiary education (33\% of 25-29-year-olds in 2053, compared to $19 \%$ in 2008), but the share of the population with higher levels of education will increase among the age groups 50 and older, as better educated cohorts will replace cohorts with lower levels of educational attainment ("educational upgrading"). This means that the share of Germans aged 50 and older with a tertiary degree was $21 \%$ in 2008, and is projected to be $34 \%$ in 2053 .

Keeping the labor force participation profiles fixed at the levels observed in 2008 and combining them with the education-specific population projections leads to an absolute labor force size of 29.6 million in 2053, which represents a reduction of almost one-third compared to 2008. This projected decline in the number of economically active individuals in Germany, based purely on changes in the demographic structure, has appeared in previous research [31]. However, by including the educational dimension, we can also offer some estimates regarding the educational composition of the future labor force: the share of the labor force with tertiary education was $25 \%$ in 2008 , but it is projected to rise to $33 \%$ in 2033, and to increase further to $41 \%$ in 2053 (compare Table 1). Since participation is held constant, this change is solely due to the changes in the composition of the German population described above. Table 1 shows that this change is expected to happen among all of the age groups, although to varying degrees.

Based on the observation of past trends in Germany and other aging countries, increases in the labor force participation rates of women and of people over age 50 are likely. In order to estimate what the consequences of these anticipated future developments would be, we calculated an additional scenario in which we assumed that participation would, by 2053, reach the levels that were observed in Sweden in 2008. Sweden is often cited as a role model country when it comes to equality in economic activity levels among men and women and to the labor force participation of workers over age 50. For example, in 2008 the labor force participation rate of 60-64-year-olds was $61 \%$ in Sweden, but only $36 \%$ in Germany.

Under the assumptions of this second scenario, we can see that the total size of the labor force is still set to decline, but only to 33.7 million: this represents a reduction of $20 \%$, rather than the reduction of over $30 \%$ that is anticipated to occur in the constant scenario. Since the total population of Germany is projected to decline as well - from 83 million in 2008 to roughly 70 million in 2053- the support ratio will only decline significantly under the first scenario: from 0.51 in 2008 to 0.42 in 2053. The support ratio here is defined as the ratio of persons in the labor force to those not in the labor force, including the population below age 15. Under 
Table 1. Share of the German labor force with tertiary education, 2008 and 2053 (constant participation scenario).

\begin{tabular}{lll}
\hline Age-group & $\mathbf{2 0 0 8}$ & $\mathbf{2 0 5 3}$ \\
\hline $\mathbf{2 5 - 2 9}$ & $21 \%$ & $36 \%$ \\
$\mathbf{3 0 - 4 9}$ & $29 \%$ & $49 \%$ \\
$\mathbf{5 0 +}$ & $30 \%$ & $44 \%$ \\
Overall (25+) & $28 \%$ & $46 \%$ \\
\hline
\end{tabular}

Source: Loichinger (2012), own calculations.

doi:10.1371/journal.pone.0108501.t001

the assumption of Swedish participation rates, the support ratio in 2053 would still be 0.49 . In terms of the educational composition of the future labor force, the two scenarios show only very minor differences.

\section{Greener? - Demographic change and the environment}

Demographic change has important consequences for the environment and for carbon emissions. In the literature that dates back to the IPAT equation [32], population size was the demographic factor that received the most attention. More recently, the study of the role of population composition has become more prominent [33].

Population aging is a process that entails substantial changes in the population age structure. It has been shown that the profile of per capita $\mathrm{CO}_{2}$ emissions by age has an inverted-U shape [34]. As individuals enter adulthood, they tend to consume and travel more, which in turn leads to a higher level of emissions. This trend continues well into adulthood, as older people have larger incomes and larger houses and cars. Emissions then decline when individuals retire and travel less. At an aggregate level, the inverted- $\mathrm{U}$ profile of emissions over the life-cycle means that a changing age structure may generate considerable reductions in $\mathrm{CO}_{2}$ emissions, all else being constant.

Figure 3 shows the trend in emissions for Germany, obtained by multiplying the age-specific per-capita profile in Zagheni [34] and UN population projections [24]. The profile of emissions over the life course is kept constant: changes in emissions are driven by changes in population size and age structure. In our stylized model, we assume that the relative age-profile of emissions for Germany is qualitatively similar to the one of the US and other developed countries. Under that assumption, we observe that population aging initially tends to increase emissions as a growing number of people pass through the ages at which emissions peak. We expect that the effect of changing population size and age structure may contribute to an increase in emissions of more than $30 \%$ over several decades, from 1950 to 2020 . But in the long run, as the proportion of people older than age 80 continues to increase and the population size shrinks, emissions would decrease and reach pre-1950 levels, under the assumption that the age-specific behavioral contribution to emissions would not change.

The combined effects of a reduced population size and a more favorable age structure (in terms of carbon emissions) are likely to generate substantial reductions in $\mathrm{CO}_{2}$ emissions. These gains will not happen in isolation. New lifestyles, increased levels of wealth, and the development of new technologies will interact with the changing demographic landscape. However, this is a case in which population aging could be appropriately leveraged to transform a challenge into an opportunity.

\section{Richer? - Demographic change and intergenerational transfers}

The impact of population aging on intergenerational transfers has been studied extensively (e.g., [35]). However, the effects of demographic change on the size and timing of bequests over the life course have not received as much attention.

The relationship between demography and bequests is complex, and is mediated by a number of economic variables, like saving rates and wealth accumulation. However, the demographic forces that shape intergenerational transfers in the form of bequests are relatively simple.

Increasing longevity and fertility postponement affect, in opposite directions, the points in time over the life course when people receive bequests. Increasing life expectancy means that, all else being constant, people will experience the deaths of their family members later in life. Thus, on average, individuals will receive bequests later in life. Fertility postponement acts in the opposite direction. Later childbearing means that, all else being equal, people in the same age group will have, on average, older parents and grandparents. In the US, life table calculations and empirical evidence from the Panel Study of Income Dynamics (PSID) indicate that the rapid increase in the mean age at childbearing has more than counteracted gains in life expectancy in recent years [36].

Lower fertility means that bequests are shared among a smaller group of people; thus the per capita amounts that individuals receive should be larger. As fertility has reached below-replacement levels, we expect that the per capita amounts of bequests people receive will stabilize.

In order to gain insight into the relative importance of changes in life expectancy and the postponement of childbearing in Germany, we evaluated trends in the life expectancy at the mean age at childbearing. This figure is a proxy for the number of years a surviving woman would expect to live with her mother alive. It can also be thought of as the average age at which a woman would experience the death of her mother, conditional on the woman's survival. Trends in the age at the mother's death can be seen as indicative of general trends in the age at the receipt of bequests.

Figure 4 shows trends in female life expectancy at the mean age at childbearing for Germany. Overall, the general trend indicates that people inherit wealth, on average, at a later stage of their life course. The general increase in life expectancy at the mean age at childbearing seems to have stalled during the past decade, as fertility postponement counteracted gains in life expectancy. However, in the coming decades, we expect to see that the effect of continued gains in life expectancy will prevail. Assuming that people do not dis-save during retirement and that fertility remains low, gains in life expectancy, coupled with the smaller size of younger generations, may also translate into larger per capita inheritance. 


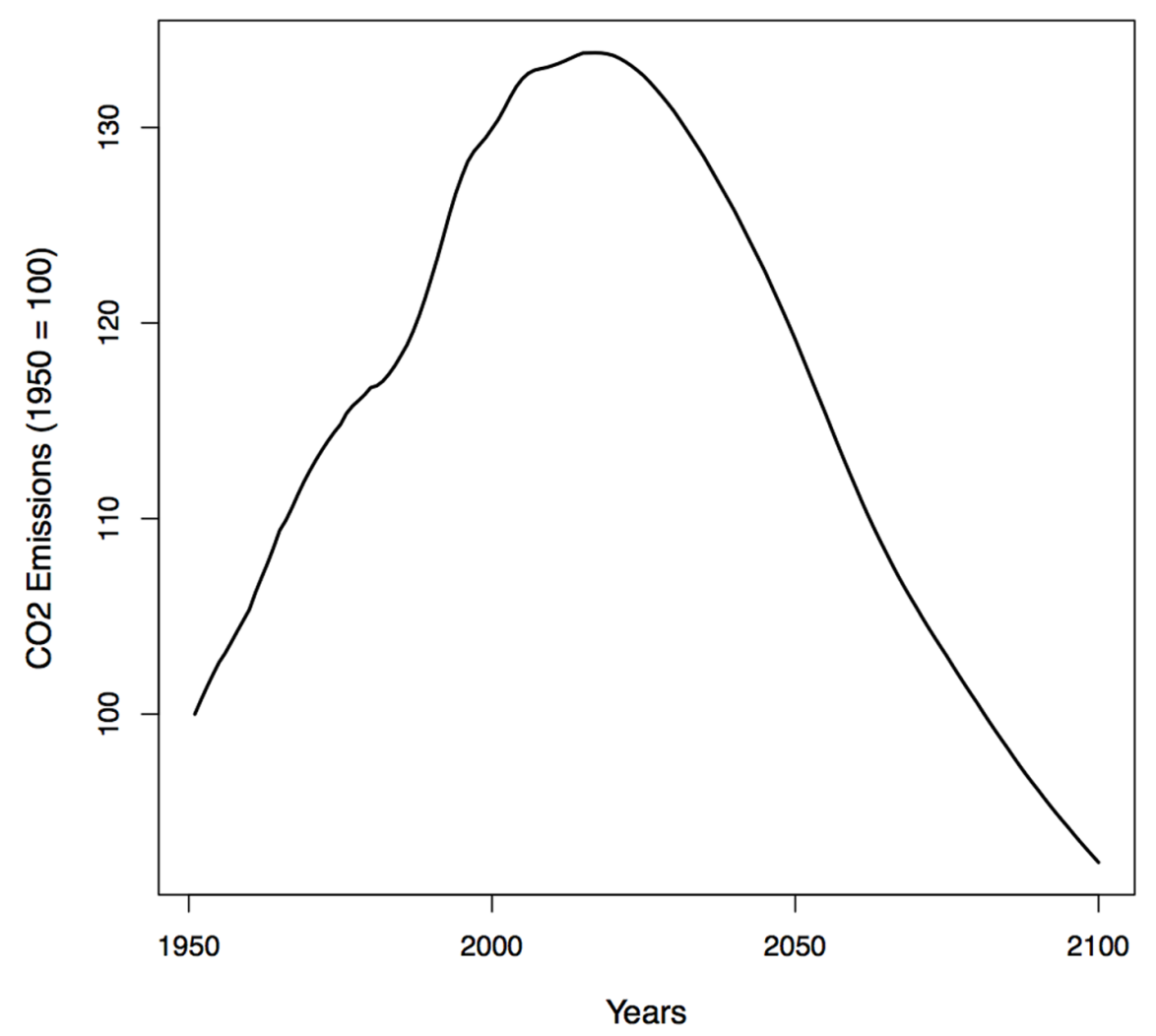

Figure 3. Relative change in $\mathrm{CO}_{2}$ emissions attributable to changes in population size and age structure affecting the sum of agespecific consumption patterns, Germany, 1950-2100. Source: Zagheni (2011), UN population projections, own calculations. doi:10.1371/journal.pone.0108501.g003

As the age at which people experience the death of a family member is expected to increase over time, individuals will receive bequests, on average, when they are older; i.e., after they have established themselves professionally and are potentially close to retirement. Bequests may thus act as a form of equalizer. The family members who stand to benefit the most from the bequestsalbeit indirectly-could be the grandchildren, who may receive financial help from their parents as they attend college or form a family.

An increase in the age at which bequests are received is not necessarily advantageous or disadvantageous. However, it can be seen as an opportunity in an aging society. Appropriate policies regarding inheritances could be designed to reduce inequality and favor intergenerational transfers to those who are at a stage of their life-cycle in which they require more resources.

\section{Healthier? - Demographic change and healthy life expectancy}

The projected increases in longevity in the coming decades are substantial. In Germany, life expectancy at birth for females will rise from 83 years currently to around 90 years by 2050. In the past, gains of roughly 2.5 years were added every 10 years. These projected changes in longevity raise the question of whether the lifetime added will be spent in good health. There are several studies on current and past trends in health expectancies, including disability-free and active life expectancy [37]. They have shown improvements in health expectancies for Germany and other developed countries as measured by different indicators of limitations in the activities of daily living or of subjective health perceptions [38-41]. However, other studies have found that these gains in disability-free life expectancy have been accompanied by an increase in the prevalence of chronic diseases [42,43].

Surprisingly, there are relatively few analyses of future health expectancy trends in Germany. These trends are mainly considered in studies on future expenditures on health care and long-term care in aging welfare states $[11,13,15,16]$. Increasingly, studies have found indications that long-term care expenditures tend to be concentrated at the end of life, during the two years prior to death $[44,45]$. This suggests that the increases in life expectancy are not necessarily related to soaring health care costs. However, the question remains if Germans enjoy not just longer lives, but healthier lives as well. In an effort to answer this question, we have forecasted age-and sex-specific trends in selfperceived health and the care needs of household members.

The analysis is based on micro-level data collected in the German Socio-Economic Panel Study (SOEP). The SOEP is a representative household panel study that reaches back to 1984 , and interviews all of the adult household members over age 17 on an annual basis. In the first wave, 12,000 respondents were interviewed. Subsets for foreigners, eastern Germans (in 1990), and immigrants were added subsequently; and in 1998, 2006, and 2009, "refreshment" samples were included. The participating households are followed over time. The SOEP contains information about each individual respondent, including his or her working history, income parameters, and household structure. Detailed descriptions of the panel design and description of the data have been provided elsewhere $[33,36]$.

The SOEP data are organized into different datasets. For our analysis, we matched the data elicited in individual-level questionnaires with biographic data and health and disability information. We chose the question "How would you describe 


\section{Germany}

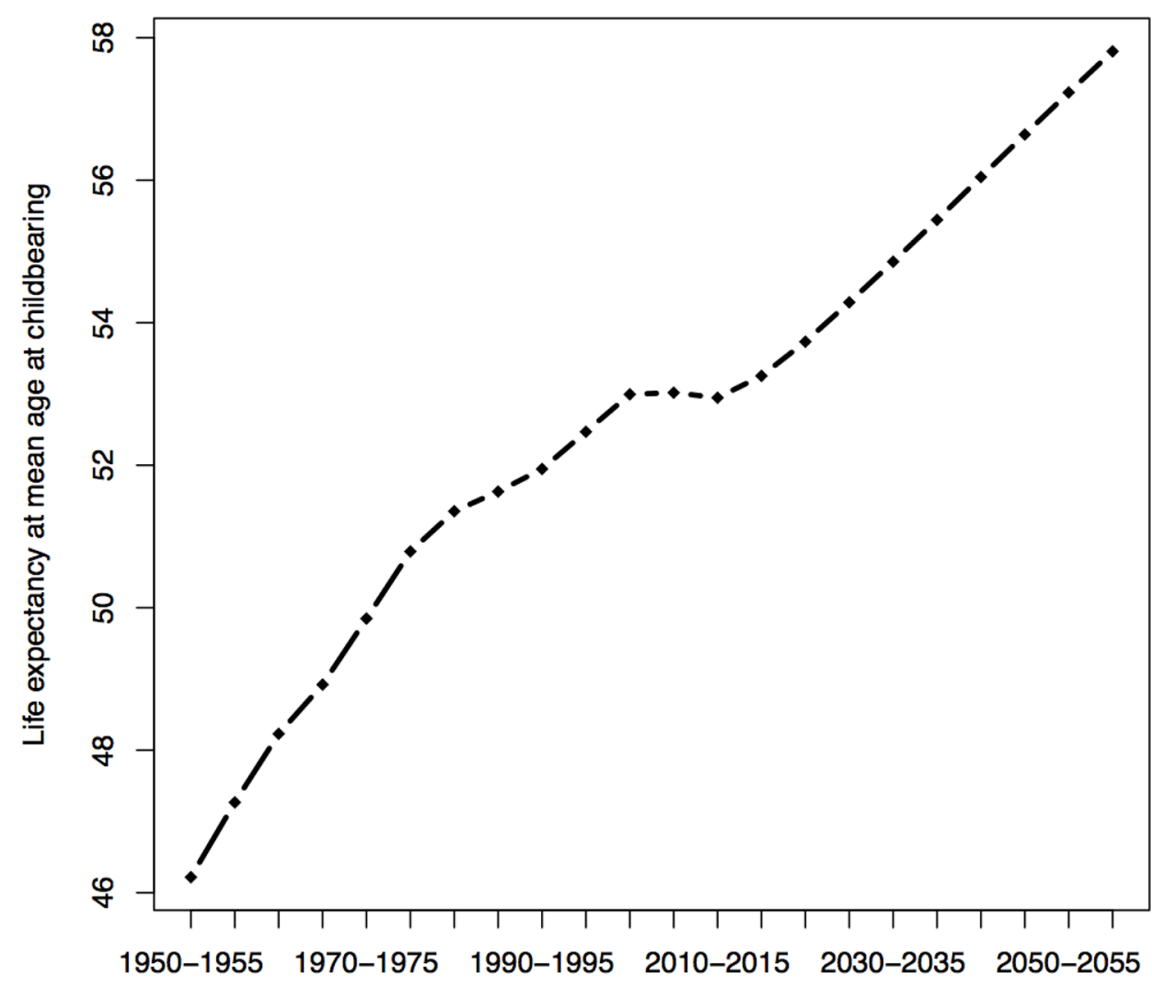

Figure 4. Estimates and projections of female life expectancy at the mean age at childbearing in Germany for the period 19502060. Source: Own calculations using demographic rates from the UN World Population Prospects: the 2012 Revision. doi:10.1371/journal.pone.0108501.g004

your health at present?" as an indicator for self-perceived health status; and the question "Is there anyone in your household who is receiving care because of old age or health reasons?" as an indicator for care need among the elderly members of the household. This question reflects the general need of care among older family members and spouses and, indirectly, at which ages this need is expressed for the first time. The self-perceived health question was asked between 1992 and 2011, and had five possible answers: "very good", "good", "satisfactory", "poor" and "very poor". We dichotomized this variable with the first three answers, which meant that the respondent was healthy. The care question was asked between 1984 and 2011, and had only two possible answers: "yes" and "no". Unfortunately, the SOEP does not contain information on elderly living in residential homes for the period of observation. This leads to an underrepresentation of individuals receiving care. However, we base our estimation on onset of care need rather than the quantity of care needed. We assume that the onset of care need does not necessarily differ between individuals receiving care at home or in residences and that family members may move to residences only when they expect to need care. Moreover, spouses may care for each other at home. We used this information to calculate the sex-specific mean age at which good health/bad health and no need for care/need for care was reported. In a second step, we forecasted these trends using a random walk with drift.

Our results confirm the findings from the literature. Between 1984 and 2011, the average age at which need for care is reported for the first time rose by 13 years, from 36 to 49 years, among women. Assuming that the pace of improvement is similar in the future, women could add another 19 years of life reaching 68 years, before they would need to care for a household member. When we used self-rated health status as an indicator to project healthy life expectancy, the numbers did not differ considerably. In this case, we see immense improvements in healthy life expectancy in recent decades. Over the entire observation period, more than 25 years of life without any subjective health difficulties are added (for the results compare Figure 5). The improvements are less pronounced among women than they are among men, but they are still large. This discrepancy may be partially caused by men's tendency to report better health than they objectively have [46].

Figure 6 shows the results in relation to life expectancy. We used data for Germany from the Human Mortality Database for the years 1956 to 2011 and the Lee-Carter-Method to forecast future life expectancy at birth [47]. Both of the indicators show a significant increase in the share of the lifetime spent in good health and with no care need. We estimate that the average man will spend around $80 \%$ of his lifetime in good health in 2050, compared to $63 \%$ today. The gap between men and women is slightly bigger in this case due to the higher life expectancy among women. In 2050, the share of the lifetime spent in good health is expected to be seven percentage points lower among women than it is among men. Still, the average woman in 2050 will likely spend over $70 \%$ of her lifetime in good health, compared to less than $50 \%$ in the past and about $60 \%$ today. According to our estimates, the onset of care need for spouses or elderly members of the household will be pushed to higher ages. Based on the development of care need since 1984, for the future our results suggest that we will spend the majority of our life time without someone in the household who needs care. 


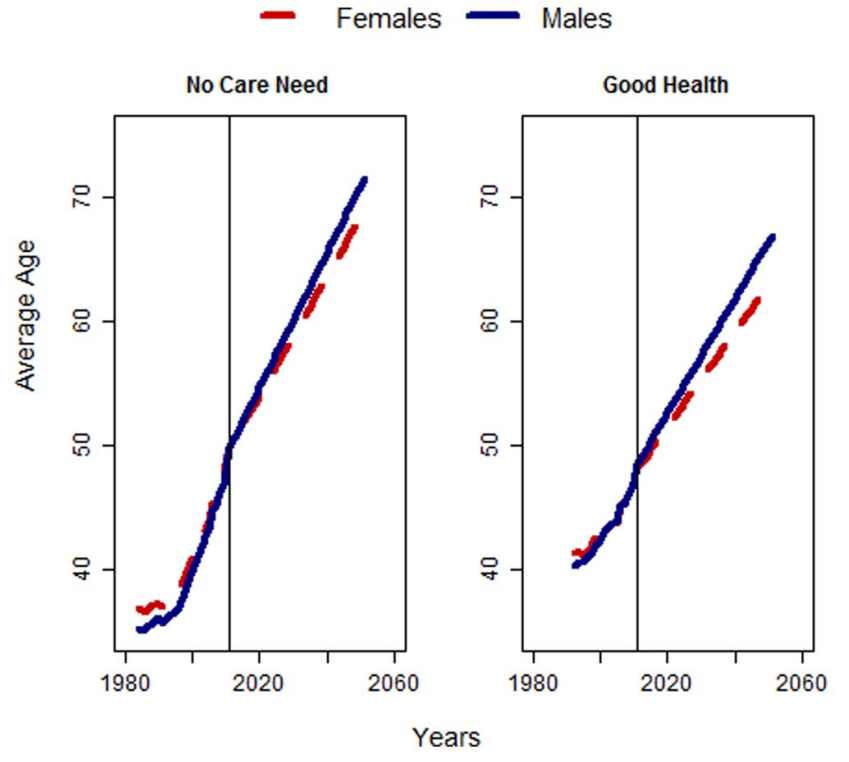

Figure 5. Projected average age until no care need is reported by any elderly household member (left) and good selfperceived health (right), men and women, Germany 19842050. Source: GSOEP 1984-2011, own calculations.

doi:10.1371/journal.pone.0108501.g005

\section{Life-cycle adjustments? - Demographic change and time use}

The ratio of market work, housework, and leisure over the lifecycle and in cross-section is of increasing importance, both between the sexes and across the life-cycle at the individual level. As the population ages and the pressure for women to participate in the labor force grows, this area is expected to undergo significant changes, which will in turn have an impact on the current generational and gender contract. We estimated and studied monetary estimates of income, consumption, and intergenerational transfers obtained by following the standard methodology of the National Transfer Accounts. This process provided us with age-specific economic variables which were also decomposed by gender. The theoretical framework was built upon Samuelson [48], Diamond [49], and Lee [50]. Information about consumption, income, and the age utilization of public expenditures and revenues came from the database for Germany [51]. To estimate production, consumption, and transfers in the household, the Time Use Survey 2001/02 was employed. The observed differences in time use by gender provide information about the division of domestic work within households, and the overall workload of an individual. While working hours in market employment were found to be twice as high for men as they are for women, the reverse was shown for domestic labor. Women were found to perform two-thirds of the domestic services, including general housekeeping tasks, childcare, elderly care, and shopping (Table 2).

Market consumption and labor income, as well as the corresponding difference between the two, or the life-cycle deficit, show a not surprising pattern. We found that men tend to produce twice as much labor income as women beginning in their thirties. As the consumption levels were found to be relatively comparable, the average woman was not shown to have a surplus over her life course. This picture changes dramatically if we include unpaid home production. For almost all of the items, such as cooking, cleaning, or shopping, women have significantly higher values of

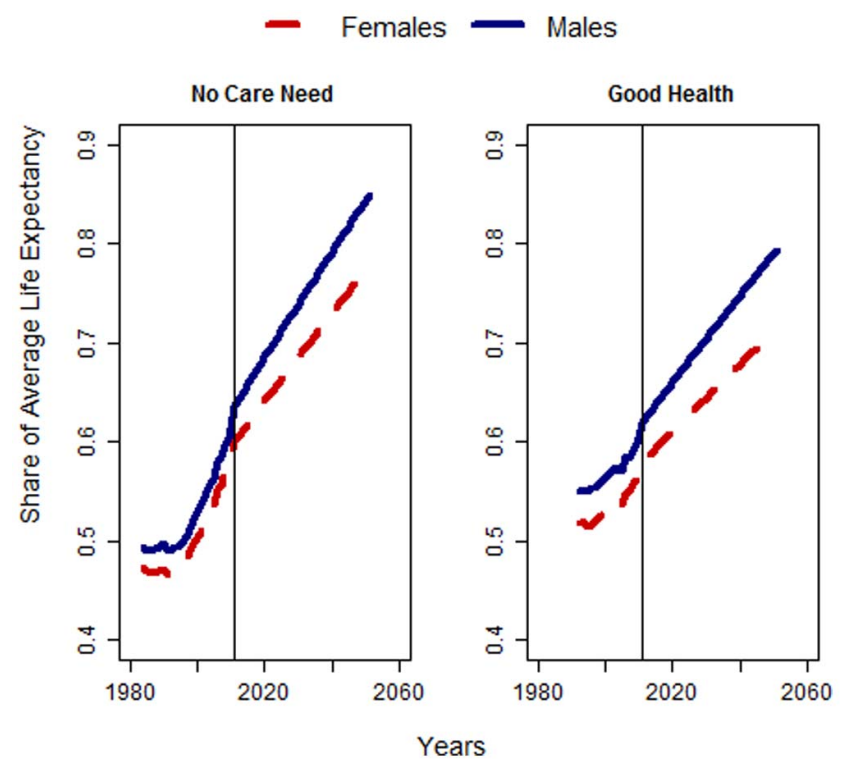

Figure 6. Share of lifetime spend with no care provision for any elderly household member and good health, men and women, Germany 1984-2050. Source: GSOEP 1984-2011, UN population projection.

doi:10.1371/journal.pone.0108501.g006

hours worked. Only from retirement age onward were men shown to increasingly engage in cooking, cleaning, and gardening. We used the specialist replacement method to monetize unpaid housework according to the third-party rule [52], we use the hourly wage of an unskilled worker for all easy household tasks. When we combined market and unpaid home production by age and gender, we found roughly similar life-cycle patterns of consumption and income for both sexes. The monetized results for the lifecycle deficit with and without household production and consumption are shown in Table 3.

The relationship between leisure, market work, and housework is expected to change in the future, assuming the currently observed profiles continue, as is shown in Table 4. At the population level, we found that the amount of time devoted to home production is likely to exceed the time spent performing market work. The amount of time spent on market work as a share of the total time available was only $14.5 \%$ in 2010 , and is expected to decrease to $11.9 \%$ by 2060 . The analysis showed that the share of time spent in what we call leisure - i.e., activities other than market work, home production, or sleeping - is set to increase slightly over the study period among the older population. For the average individual (in this synthetic cohort approach), we found that the share of time spent working is projected to be $7.4 \%$, while the share of time spent in leisure activities is likely to account for nearly half of the person's lifetime. Thus, the aging of the population will lead to an increase in leisure time, if no further adjustments are made.

It would be interesting to estimate a scenario assuming participation rates of Swedish men and women but time transfers for Sweden are not yet available. Still, with a simple ten percentage points increase in female labor force participation we can assume the iso-work amount to stay constant. In response, females could reduce hours in unpaid domestic labor. We find that 47 million hours of work would need to be redistributed on the population level. About 30,000 individuals working on average 30 hours per week would be needed to close the gap. In case the 
Table 2. Hours spent on housework per day by gender.

\begin{tabular}{lllll}
\hline & & & & \\
\hline & $<\mathbf{3 0}$ & $\mathbf{3 0 - 6 5}$ & $\mathbf{6 5 +}$ & 3.7 \\
\hline Men & 1.3 & 2.8 & 4.9 & \\
\hline
\end{tabular}

Source: Time Use Survey 2001/02, Germany.

doi:10.1371/journal.pone.0108501.t002

excess housework is split between household members each adult had to increase weekly working hours by about 45 minutes.

\section{Discussion}

In this paper, we addressed the important question of how selected areas of life will be affected as populations grow older and smaller. We used the case of Germany, a country that is at a relatively advanced stage of the demographic transition, to study the potential long-run implications of population aging. In the decades prior to 2040, the consequences of population aging are expected to be largely negative, as the baby boomers reach retirement age and dependency ratios and expenditures for pensions and health care increase. Still, we found evidence that after a period of transition, population aging could have effects that are positive, at least in part.

We have shown the potential effects of having an older and smaller population, such as lower carbon emission levels due to changes in aggregate consumption patterns. Having a higher share of the population with tertiary education could be beneficial for economic growth in the long run, and could compensate, at least in part, for absolute and relative declines in the number of economically active persons. Inherited wealth will have to be split among a smaller number of siblings, which could compensate for an increase in upward public transfers, via pay-as-you-go pension system. Furthermore, individuals are expected to spend longer shares of their lives in good health and engage in leisure activities.

The results only take into account pure demographic changes, as we chose to look at only the changes related to shifts in the population composition, and their impact on different areas of society. Given this limitation, we were unable to predict whether behavioral changes will occur as individuals adapt to an older population structure. We are aware that changing expectations will alter today's observed profiles.

The higher educational attainment at the population level can be advantageous for economic growth. Whether this development, through presumed increases in productivity, can compensate for the negative long-run effects of the shrinking workforce remains to be seen. The positive returns of education might be smaller in the future, when larger shares of each cohort attain higher levels of educational attainment than it is currently the case. The expected reduction in the levels of carbon emissions due to population decline could be even greater if more environmentally-friendly technologies are adopted. On the other hand, emissions could also stagnate, as shrinking populations might not be able to realize significant $\mathrm{CO}_{2}$ reductions. For example, more individuals may be living in smaller or single households that are not efficient in terms of per capita energy use. The higher educational attainment could also be disadvantageous for the level of $\mathrm{CO}_{2}$ emissions as individuals with tertiary education tend to travel more. The bequests received by future generations could be significantly lower than our estimates if their parents plan for longer lives and adapt to increasing longevity by using/depleting their capital stock. Moreover, the projected increase in healthy life expectancy is difficult to estimate. The question of whether the time spent in intensive care will really be postponed to the last two years of life, as some studies have proposed [45,53], remains open. Trends in dementia, for example, are not entirely clear [54,55]. Furthermore, given the increases in the pension entitlement age in most developed countries, the share of the lifetime spent working could remain constant instead of declining.

Nevertheless, the results show that there are important areas in which population aging and decline could be beneficial. Projecting the behavioral changes in each of these areas is beyond the scope of this article, but this is an obvious topic for future research. Although the results presented refer to Germany, they could be of interest for other regions around the world, including both developed and developing countries. Life expectancy is increasing almost universally, and the health status of the older population is improving. The importance of investments in education is well known, and education levels are increasing in the great majority of countries. Depending on a country's stage in the demographic transition process, the results from the analyses of bequests and $\mathrm{CO}_{2}$ emissions are also generalizable.

Table 3. Market and non-market values for consumption, income, and corresponding lifecycle deficit in billion euros, Germany 2003.

\begin{tabular}{|c|c|c|c|}
\hline & Men & Women & Total \\
\hline Consumption & 725 & 781 & 1506 \\
\hline Income & 814 & 429 & 1243 \\
\hline Market Lifecycle Deficit & 89 & -352 & -263 \\
\hline Time adjusted consumption & 1,131 & 1,202 & 2,333 \\
\hline Time adjusted income & 1,124 & 946 & 2,070 \\
\hline Time adjusted lifecycle deficit & -7 & -256 & -263 \\
\hline
\end{tabular}

Source: own calculations.

doi:10.1371/journal.pone.0108501.t003 
Table 4. Percentage share of activities at the population level, Germany 2010 and 2060.

\begin{tabular}{llll}
\hline & & & \\
\hline & Housework & Work & Leisure \\
\hline 2010 & 20.5 & 14.5 & 65.0 \\
2060 & 21.8 & 11.9 & 66.3 \\
\hline
\end{tabular}

Source: Time Use Survey 2001/02, own calculations.

doi:10.1371/journal.pone.0108501.t004

Some aspects of population aging are an inevitable consequence of demographic change. In this article, we showed examples of situations where population aging can lead to important opportunities for our societies. We believe that a continued discussion about these issues between social scientists and policy makers will be crucial to leverage the benefits of changing population compositions.

\section{References}

1. Oeppen J, Vaupel JW (2002) Broken limits to life expectancy. Science 296: 1029-1031.

2. Frejka T, Sobotka T (2008) Overview Chapter 1: Fertility in Europe: Diverse, delayed and below replacement. Demographic Research 19: 15-46.

3. Cutler DM, Poterba JM, Sheiner LM, Summers LH (1990) An Aging Society: Opportunity or Challenge? Brookings Papers on Economic Activity 1: 1-73.

4. Muszyńska MM, Rau R (2012) The Old-Age Healthy Dependency Ratio in Europe. Journal of Population Ageing 5: 151-162.

5. Börsch-Supan A (2003) Labor market effects of population aging. Labour 17: 5 44 .

6. Börsch-Supan A (2004) Global Aging: Issues, Answers, More Questions. MEA Discussion Paper 55-2004.

7. Falkenstein M, Möller J, Staudinger UM (2011) Age, aging and laborconsequences for individuals and institutions. Journal for Labour Market Research 44: 293-294.

8. D'Addio AC, Keese M, Whitehouse E (2010) Population ageing and labour markets. Oxford Review of Economic Policy 26: 613-635.

9. Börsch-Supan A (2008) The impact of Global Aging on Labor, Product, and Capital Market. In: Prskawetz A, Bloom D, Lutz W, editors. Population Aging, Human Capital Accumulation, and Productivity Growth: Wiley-Blackwell. pp. $52-77$.

10. Bloom D, Canning D (2008) Global Economic Change: Dimensions and Economic Significance. In: Prskawetz A, Bloom D, Lutz W, editors. Population Aging, Human Capital Accumulation, and Productivity Growth: Wiley-Blackwell. pp. 17-51.

11. Getzen TE (1992) Population aging and the growth of health expenditures. Journal of Gerontology 47: 98-104.

12. McGrail K, Green B, Barer M, Evans R, Hertzman C, et al. (2000) Age, costs of acute and long-term care and proximity to death: evidence for 1987-88 and 1994-95 in British Columbia. Age and Ageing 29: 249-253.

13. Anderson GF, Hussey PS (2000) Population aging: a comparison among industrialized countries. Health Affairs 19: 191-203.

14. de la Maisonneuve C, Martins JO (2013) Public Spending on Health and Longterm Care: A New Set of Projections. OECD Economics Department Working Papers, próxima publicación.

15. Schulz E, Leidl R, König H (2004) The impact of ageing on hospital care and long-term care-the example of Germany. Health Policy 67: 57-74.

16. Comas-Herrera A, Wittenberg R, Costa-Font J, Gori C, Di Maio A, et al. (2006) Future long-term care expenditure in Germany, Spain, Italy and the United Kingdom. Ageing and Society 26: 285-302.

17. Sanderson WC, Scherbov S (2010) Remeasuring aging. Science (Washington) 329: $1287-1288$

18. Betts K (2014) The aging of the Australian population: triumph or disaster? A report prepared for the Monash Centre for Population and Urban Research.

19. Bongaarts J (2004) Population aging and the rising cost of public pensions. Population and Development Review 30: 1-23.

20. Jimeno JF, Rojas JA, Puente S (2008) Modelling the impact of aging on social security expenditures. Economic Modelling 25: 201-224.

21. Fenge R, Werding M (2004) Ageing and the tax implied in public pension schemes: simulations for selected OECD countries. Fiscal Studies 25: 159-200.

22. Vogel E, Ludwig A, Börsch-Supan A (2013) Aging and pension reform: extending the retirement age and human capital formation. National Bureau of Economic Research.

23. United Nations (2011) World Population Prospects: The 2010 Revision

24. United Nations (2013) World Population Prospects: The 2012 Revision.

\section{Acknowledgments}

The authors wish to thank Jane O'Sullivan and Cassio M. Turra for their valuable comments on earlier versions of the manuscript.

\section{Author Contributions}

Analyzed the data: EL EZ FK TV. Contributed to the writing of the manuscript: EL EZ FK TV.

25. Mason A, Lee R (2006) Reform and support systems for the elderly in developing countries: capturing the second demographic dividend. Genus: 1135

26. European Commission (2010) European Union Labour Force Survey (yearly microdata files, 1983 to 2008). Eurostat.

27. Lee R, Mason A Some Macroeconomic Aspects of Global Population Aging. Demography: 151-172.

28. Ludwig A, Schelkle T, Vogel E (2012) Demographic change, human capital and welfare. Review of Economic Dynamics 15: 94-107.

29. Loichinger E (2012) Europe's future human capital: Population projections by age, sex, education, and labor force participation. Dissertation. Vienna: University of Economics and Business.

30. K.C S, Barakat B, Goujon A, Skirbekk V, Sanderson W, et al. (2010) Projection of populations by level of educational attainment, age, and sex for 120 countries for 2005-2050. Demographic Research 22: 383-472.

31. Börsch-Supan A, Wilke CB (2009) Zur mittel-und langfristigen Entwicklung der Erwerbstätigkeit in Deutschland. Zeitschrift für Arbeitsmarktforschung 42: 29 48

32. Ehrlich PR, Holdren JP (1971) Impact of population growth. Science, New Series 171, No.3977: 1212-1217.

33. O'Neill BC, Dalton M, Fuchs R, Jiang L, Pachauri S, et al. (2010) Global demographic trends and future carbon emissions. Proceedings of the National Academy of Sciences 107: 17521-17526.

34. Zagheni E (2011) The leverage of demographic dynamics on carbon dioxide emissions: does age structure matter? Demography 48: 371-399.

35. Lee R, Mason A (2011) Population Aging and the Generational Economy. Cheltenham, UK.: Elgar, Edward.

36. Zagheni E, Wagner B (2014) The Impact of Demographic Change on Intergenerational Transfers via Bequests. IIASA Interim Report IR-14-002.

37. Christensen K, Doblhammer G, Rau R, Vaupel JW (2009) Ageing populations: the challenges ahead. The Lancet 374: 1196-1208.

38. Doblhammer G, Kytir J (2001) Compression or expansion of morbidity? Trends in healthy-life expectancy in the elderly Austrian population between 1978 and 1998. Social Science \& Medicine 52: 385-391.

39. Manton KG (2008) Recent declines in chronic disability in the elderly US population: risk factors and future dynamics. Annual Review of Public Health 29: 91-113.

40. Ziegler U, Doblhammer G (2008) Cohort changes in the incidence of care need in West Germany between 1986 and 2005. European Journal of Population/ Revue européenne de Démographie 24: 347-362.

41. Unger R (2006) Trends in active life expectancy in Germany between 1984 and 2003-a cohort analysis with different health indicators. Journal of Public Health 14: 155-163.

42. Parker MG, Thorslund M (2007) Health trends in the elderly population: getting better and getting worse. The Gerontologist 47: 150-158.

43. Crimmins EM (2004) Trends in the health of the elderly. Annual Review of Public Health 25: 79-98.

44. Breyer F, Felder S (2004) Life Expectancy and Health Care Expenditures in the 21st Century: A New Calculation for Germany Using the Costs of Dying. DIW Discussion Paper.

45. Zweifel P, Felder S, Meiers M (1999) Ageing of population and health care expenditure: a red herring? Health Economics 8: 485-496.

46. Oksuzyan A, Juel K, Vaupel JW, Christensen K (2008) Men: good health and high mortality. Sex differences in health and aging. Aging Clinical and Experimental Research 20: 91-102. 
47. Lee RD, Carter LR (1992) Modeling and forecasting US mortality. Journal of the American Statistical Association 87: 659-671.

48. Samuelson PA (1958) An Exact Consumption-Loan Model of Interest with or without the Social Contrivance of Money. The Journal of Political Economy 66: $467-482$.

49. Diamond PA (1965) National Debt in a Neoclassical Growth Model. The American Economic Review 55: 1126-1150.

50. Lee RD (1994) The Formal Demography of Population Aging, Transfers, and the Economic Life Cycle. In: Martin LG, Preston SH, editors. Demography of Aging: National Academy Press Washington, DC 1994. pp. 8-49.
51. Kluge FA (2009) Transfers, consumption and income over the lifecycle in Germany. MPIDR Working Paper WP-2009-014.

52. Reid MG (1934) Economics of household production: J. Wiley \& Sons, Inc.

53. Breyer F, Felder S (2006) Life expectancy and health care expenditures: A new calculation for Germany using the costs of dying. Health Policy 75: 178-186.

54. Schrijvers EM, Verhaaren BF, Koudstaal PJ, Hofman A, Ikram MA, et al (2012) Is dementia incidence declining? Trends in dementia incidence since 1990 in the Rotterdam Study. Neurology 78: 1456-1463.

55. Rocca WA, Petersen RC, Knopman DS, Hebert LE, Evans DA, et al. (2011) Trends in the incidence and prevalence of Alzheimer's disease, dementia, and cognitive impairment in the United States. Alzheimer's \& Dementia 7: 80-93. 